\title{
Xenarthras: topografia intestinal e relações vasculares com a serosa
}

[Xenarthras: intestinal topography and vascular relationships with serosa]

$$
\text { P. Carvalho }{ }^{1} \text {, L.C. Rezende }{ }^{2} \text {, J.R. Ferreira }{ }^{1 *}
$$

${ }^{1}$ Universidade de Brasília - Faculdade de Medicina - Brasília, DF

${ }^{2}$ Universidade Federal do Mato Grosso - Instituto de Ciências da Saúde - Sinop, MT

\section{RESUMO}

Xenarthras (Mammalia, Dasypodidae) das espécies Dasypus novemcinctus e Euphractus sexcinctus tiveram sua anatomia científica estudada em relação à topografia dos intestinos delgado e grosso, suas relações peritoniais, morfologia externa e irrigação. Medidas dos diferentes segmentos intestinais e do número de vasos a eles destinados foram tomadas para fins comparativos. O método previu: fixação (formol 7\%); injeção de látex; dissecação e fotodocumentação. Espacialmente, embora os intestinos sejam fixados por dupla membrana peritoneal, como em outros vertebrados, nestes a serosa conectou o duodeno, o jejuno, o íleo e os cólons em um único ligamento fixado no dorso do animal. Duodeno e pâncreas, intraperitoniais, como o reto, fixaram-se nas pelves maior e menor, respectivamente e dorsalmente. Vasos derivados do tronco celíaco mesentérico e da aorta percorreram o interior do mesoduodeno, do mesentério comum, do mesocólon e do mesorreto, estando estes, ao longo de seus trajetos, relacionados às cadeias linfonodulares intestinais. O modelo de rotação peritoneal, a morfologia externa, bem como o modelo de vascularização intestinal, foram interpretados como basais, diferindo dos vertebrados recentes, conforme o suporte literário.

Palavras-chave: Dasypodidae, intestino, artéria mesentérica, peritônio, vascularização

\begin{abstract}
Xenarthras (Mammalia, Dasypodidae) of the species Dasypus novemcinctus and Euphractus sexcinctus had their scientific anatomy studied in relation to the topography of the small and large intestines, their peritoneal relationships, external morphology and irrigation. Measurements of the different intestinal segments and the number of vessels destined for them were taken for comparative purposes. The method predicted: fixation (7\% formaldehyde); latex injection; dissection and photo documentation. Spatially, the intestines, although fixed by a double peritoneal membrane, as in other vertebrates, in these, the serosa connected the duodenum, jejunum, ileum, and the colon in a single ligament fixed to the animal's back. Duodenum and pancreas, intraperitoneal, like the rectum, were fixed in the major and minor pelvis respectively and dorsally. Vessels derived from the mesenteric celiac trunk and the aorta traveled through the interior of the mesoduodenum, common mesentery, mesocolon and mesoride, being related to the lymph node chains along their pathways. The peritoneal rotation model, the external morphology as well as the model of intestinal vascularization were interpreted as basal, differing from recent vertebrates, according to literary support.
\end{abstract}

Keywords: Dasypodidae, intestine, mesenteric artery, peritoneum, vascularization

\section{INTRODUÇÃO}

O estudo da morfologia de animais da superordem Xenarthra (Cope, 1889) implicou observar que o seu desenho corporal é primitivo em relação a outros animais de ordens mais recentes. A literatura chamou a atenção para particularidades morfológicas do tubo digestório, vinculadas à condição evolutiva da modelação dos mesentérios e mesocólons, bem como das artérias nutridoras intestinais, inferindo que estas são primitivamente retroperitoneais, adentrando-se entre as lâminas do peritônio e fixando vísceras cavitárias (Moore e Persaud, 2008; Hyttel et al., 2010). Outro estudo

Recebido em 4 de julho de 2019

Aceito em 5 de maio de 2020

*Autor para correspondência (corresponding author)

E-mail: jussararochaferreira@gmail.com 
relatou artérias mesentérica caudal e retal irrigando o intestino primitivo de Bradypus torquatus (Ferreira et al., 2013). Alguns dados morfológicos têm sido usados para classificação e relações taxonômicas, como o hábito alimentar do animal, conforme estudo de Chaetophractus villosus (Diz et al., 2006).

Na literatura clássica, há relatos de vertebrados (roedores: Oryctolagus) com intestinos póspilóricos complexos, ceco desenvolvido, bem como da ocorrência de grande artéria nutridora das dependências dorsal e ventral do mesentério (Grassé, 1965). Existe consenso de que as anastomoses arqueadas, visíveis nos tubos intestinais de vertebrados em geral, são facilitadoras do fluxo sanguíneo nos dois sentidos em relação à origem da artéria principal, nutridora da região, podendo este vaso contribuir para minimizar a falência vascular e também para retardar ou acelerar o fluxo sanguíneo em conformidade com exigências funcionais. $\mathrm{O}$ modelo de vascularização justa-intestinal tem sido utilizado como um dos critérios para diferenciar jejuno de íleo (Llorca, 1952; Stevens e Hume, 1995; Hyttel et al., 2010).

Esta revisão literária foi motivadora do estudo em Dasypus novemcinctus e Euphractus sexcinctus, cujo propósito foi analisar aspectos morfológicos dos intestinos delgado e grosso, como: irrigação, relações dos vasos com linfonodos mesentéricos e as correlações das dependências peritoneais com as artérias intestinais e os linfonodos. Acreditando-se que estudos de anatomia científica contribuam para o conjunto do conhecimento sobre animais da biodiversidade sul-americana e fortaleçam tal conhecimento, com fins de manejo, clínica e preservação das espécies na natureza, realizou-se a presente análise em duas espécies de Xenarthras.

\section{MATERIAL E MÉTODOS}

Analisaram-se, em Xenarthras (Mammalia, Dasypodidae), aspectos da morfologia geral de segmentos do tubo digestório, relacionando-se as alças intestinais ao peritônio adjacente (mesentério e mesocólon), aos vasos sanguíneos e aos grupamentos linfonodulares regionais. Os animais utilizados no estudo vieram a óbito por morte acidental, tendo sido coletados em rodovias estaduais nos estados do Paraná e Goiás (Processo: No. UEM / Viapar: 7650/2008: Ibama:
18256) e depositados no Laboratório de Macro e Mesoscopia da FM/UNB/DF. Estão sendo reaproveitados neste estudo, conforme o princípio dos 5Rs, animais utilizados por um dos autores, no projeto intitulado "Biologia da reprodução em tatus: análise morfológica comparativa entre espécies".

As espécies eram o Euphractus sexcinctus $(\mathrm{n}=2$ machos e 2 fêmeas) e o Dasypus novemcinctus ( $\mathrm{n}=2$ fêmeas). O projeto foi aprovado pela Comissão de Ética no Uso de Animais da Faculdade de Medicina Veterinária e Zootecnica da Universidade de São Paulo, aprovado em 22/06/2011 (55589/2011). O método de preparo dos animais previu sequencialmente: coleta dos animais a fresco ou refrigerados; perfusão da aorta torácica (água aquecida $40^{\circ} \mathrm{C}$ ); preparo e injeção de látex corado no sistema arterial, com os animais a fresco (Neoprene $650^{\circledR}$ e Sulvinil Corante 2350-0003 ${ }^{\circledR}$ ); fixação dos cadáveres, durante 30 dias, com formaldeído (37\%, $\mathrm{SYNTH}^{\circledR}$ ) diluído em água a $7 \%$, seguido de conservação dos espécimes em solução aquosa (álcool etílico 70\%).

Procedeu-se, a seguir, as dissecações sob mesoscopia de luz (Equipamento: lupa Lts-Mod. $\left.3700^{\circledR}\right)$ e fotodocumentação por câmera digital (Nikon D40 ${ }^{\circledR}$ ). Durante esse processo, utilizou-se iluminação das dependências peritoneais por negatoscópio, para identificação dos grupamentos linfonodulares intraperitoneais e quantificação dos vasos mesentéricos e mesocólicos. Os dados de morfologia externa, como: fixação das alças intestinais pelo peritônio; topográfica e relações das alças intestinais foram pontos de referência para a análise da origem, do trajeto e do destino dos vasos intestinais descritos. Com foco na aorta abdominal, ramos intraperitoneais da artéria mesentérica comum foram quantificados e tabulados (fita métrica flexível e paquímetro de titânio, 6 polegadas, 150mm, MITUTOYO-530312B-10), por região intestinal.

A análise quantitativa considerou o comprimento dos segmentos dos intestinos delgado e grosso em função do número de animais e do sexo. Analisouse também o tamanho da artéria mesentérica comum, quantificando-se seus ramos colaterais primários dos segmentos intestinais: duodeno, jejuno e íleo, do íleo terminal e da ampola cecal em função do número de animais e do sexo. A denominação anatômica das estruturas 
seguiu o critério oficial (http://www.wavaamav.org/wava-documents.html;2017). Naqueles aspectos passíveis de adequação para estas espécies, nomearam-se as estruturas conforme a literatura (Ferreira et al., 2013), visto que a nomina anatômica oficial não prevê a nominação destes termos, como se seguiu: mesentério comum (mc); ́leo terminal (it); ampola cecal (ap); cólons (co) e reto (re); artéria retal (ar); artéria mesentérica comum (amco) e artéria mesentérica cranial (amcr). Os modelos de vascularização nas espécies Euphractus sexcinctus (E. sexcinctus) e Dasypus novemcinctus (D. novemcinctus) estudadas foram representados esquematicamente.

\section{RESULTADOS}

A análise dos dados morfológicos do tubo digestório de $D$. novemcinctus e de E. sexcinctus apresentou particularidades em relação a sua fixação na região dorsal da parede abdominal e no que diz respeito à morfologia externa dos segmentos dos intestinos delgado e grosso e sua vascularização. Para facilitar o entendimento da topografia abdominal e dos intestinos, imagens retrataram espécimes com peritônio íntegro (Fig.1A, D. novemcinctus; e 1B, E. sexcinctus). Ao estudarem-se as relações viscerais, analisaram-se os órgãos do compartimento cranial da cavidade abdominal, como o esôfago, o fígado e o estômago, que, fixos pelas dependências do peritônio, deram suporte às vísceras craniais, como pâncreas, duodeno, baço e raiz do jejuno (Fig. 1D, D. novemcinctus).

Todos os segmentos intestinais caudais ao estômago estiveram fixados na parede dorsal do corpo do animal através da raiz do mesentério comum aos intestinos delgado e grosso. Na grande dependência peritoneal, observaram-se três porções peritoneais interligadas fixando as alças intestinais em partes (bordas), assim denominadas: mesentério comum, mesocólon e mesoduodeno (Fig. 1A, B, C e D). Nas duas espécies, registraram-se ligamentos de peritônio específicos: ligamento hepatogástrico, ligamento duodenal, omento maior, raiz do mesentério e ligamento largo testicular. $\mathrm{O}$ mesoduodeno acomodou (em sua intimidade) o pâncreas, os vasos, os nervos e os linfonodos pancreáticos e duodenais e, em suas bordas, a alça duodenal, que se apresentou intraperitoneal juntamente com a cabeça e a parte do corpo do pâncreas. O fígado ocupou uma posição craniodorsal em relação a todas as vísceras do andar cranial da cavidade peritoneal, no antímero direito, deslocando o duodeno e o pâncreas caudalmente (Fig. 1C, D e E).

O duodeno, conectado ao estômago, acomodou o pâncreas, fixando-se à parede dorsal através da borda peritoneal mesoduodenal, em região próxima aos testículos (intracavitários) ou aos ovários, no antímero direito. $\mathrm{O}$ reto e a escavação retovesical são mediais ao ligamento supracitado (Fig. 1D) e estão contidos nas pelves maior e menor. O mesentério comum deu suporte (em sua intimidade) aos vasos, aos nervos, às alças duodenais, jejunais, ileais, à ampola cecal e aos linfonodos mesentéricos cólicos e cecais. Foi possível observar que o mesentério comum e o intestino delgado são longos (Fig. 1A e B) em relação ao comprimento do intestino grosso.

O mesocólon, em sua borda livre, acomodou os cólons cranial, transversal e caudal, dando suporte aos ramos arteriais cecocólicos, retais e cólicos da amco e aos linfonodos adjacentes (Fig. 1A; 2D e F). O primeiro segmento do intestino grosso apresentou-se como uma dilatação no final do íleo (ampola cecal), liso, sem concentração de fibras musculares em feixes, e o esfíncter anatômico da transição il $\mathrm{n}$ eocecal não foi perceptível na análise de morfologia externa. No $D$. novemcinctus, a alça terminal do íleo reduziu significativamente o calibre ao se conectar com a ampola cecal (Fig. 1A, 2F), notou-se que o cólon, um compartimento dilatado e relativamente reto, teve a alça intestinal caudal diminuída de calibre antes desta penetrar na pelve menor (Fig. 1C).

Nas duas espécies, o intestino grosso exibiu a seguinte configuração: ampola cecal (cranial direita); flexura cólica direita; cólon transversal; flexura cólica esquerda; cólon esquerdo (caudal) e reto, este último penetrou na pelve, dorsalmente à bexiga urinária no macho e ao útero na fêmea (Fig. 1C e E).

Constatou-se que a irrigação do intestino delgado dependeu da artéria aorta abdominal, de cujo ramo ventral (de três a cinco milímetros) identificado como tronco celíaco mesentérico, derivaram-se os ramos hepatogástrico e a amco (ramo colateral ventral, em $100 \%$ da amostra). O primeiro vascularizou o estômago, o baço, o fígado, a parte do pâncreas e do duodeno. $\mathrm{O}$ segundo 
vascularizou os intestinos delgado e grosso, excluindo-se a parte terminal do reto. O duodeno foi nutrido por duas artérias duodenais derivadas da amco, tendo recebido contribuições de ramos colaterais do tronco hepatogástrico.
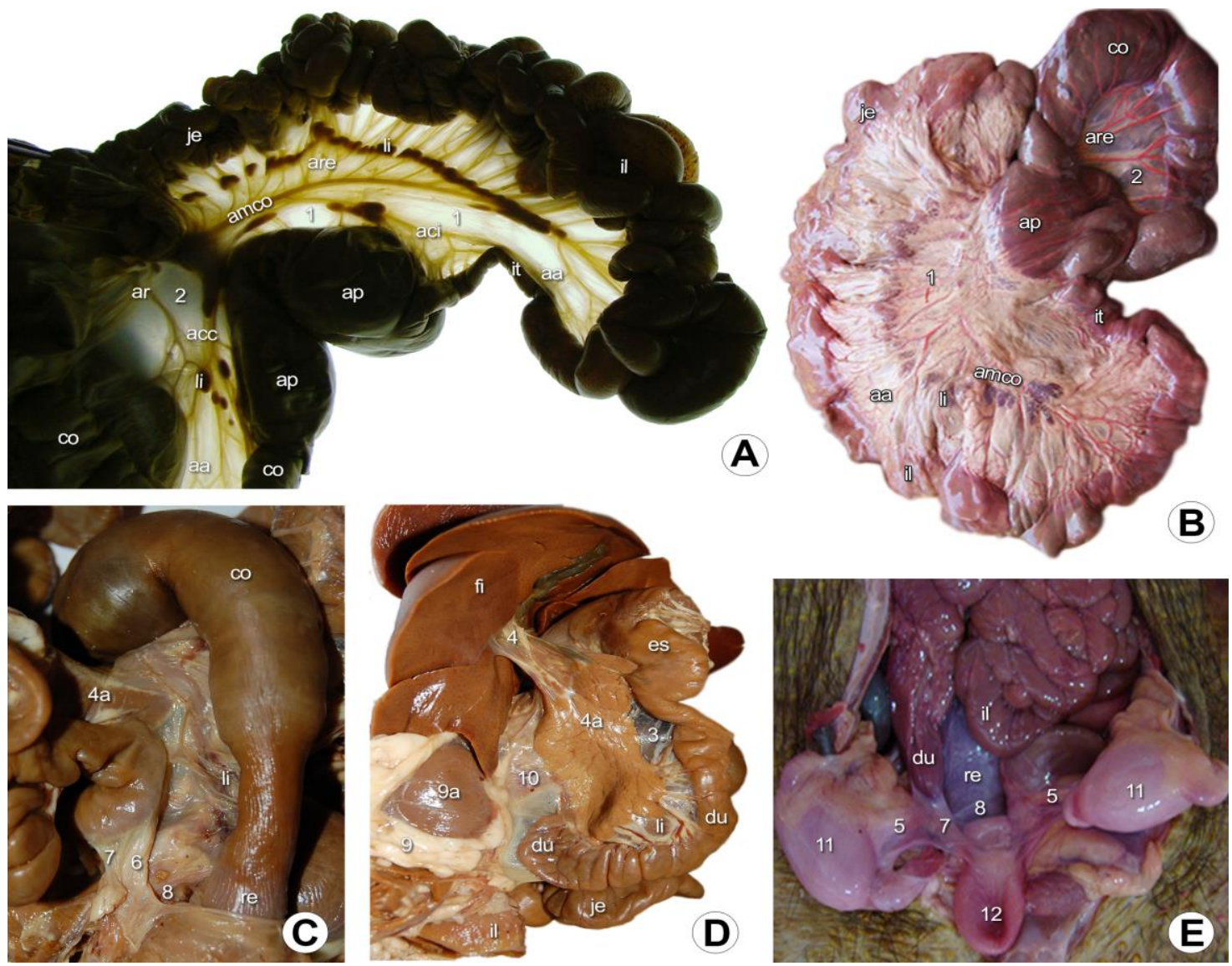

Figura 1. Imagens digitalizadas de vísceras da cavidade abdominal de tatus das espécies Dasypus novemcinctus (A, C e D) e Euphractus sexcinctus (B e E). Nestas, observa-se: primeiro, os aspectos morfológicos de vísceras abdominais e pélvicas, duodeno (du; D e E), jejuno (je; A, B e D), íleo (il; A, B e E), íleo terminal (it, A e B), ampola cecal (ap; A e B), cólon (co; A, B e C) e reto (re; C e E); segundo, vasos sanguíneos e linfonodos (A, B, C e D), artéria mesentérica comum (amco) e seus ramos colaterais primários e secundários, artérias cecocólica (acc), cecoileal (aci) e retal (ar), podendo os ramos serem retos (are), ou arqueados (aa). Detalhes dos linfonodos (li); terceiro, o peritônio e suas dependências, e as relações entre órgãos abdominais e pélvicos (A, B, C, D e E): o mesentério comum (1), mesocólon (2), mesoduodeno (3), ligamento hepatopancreático (4), pâncreas (4a), ligamento largo testicular (5), ligamento duodenal (6), raiz do mesentério (7), fundo de saco reto uterino e/ou reto vesical (8), fáscia renal e cápsula adiposa (9), rim (9a), peritônio parietal (10), túnica vaginal e testículo (11) e bexiga urinária e peritônio visceral (12).

A amco percorreu toda a extensão do mesentério comum, foi considerada longa e de grande calibre ( 17,25 centímetros de comprimento médio), tendo emitido, em média, 23 ramos colaterais primários, que foram quantificados (Tab. 1 e 2) e esquematizados (Fig. 3). Ramos colaterais secundários retilíneos e, a seguir, arqueados subdividiram-se em primeira, segunda e terceira ordem. As artérias nutrícias terminais foram retas e ocorreram próximo à borda mesentérica das alças intestinais, quando se bifurcaram ao redor da víscera e em direção à borda antimesentérica. Da porção final do terço cranial da amco, destacou-se à direita a artéria cecocólica (acc), que vascularizou a ampola cecal (junção ileocólica) e o segmento cranial cólico. 

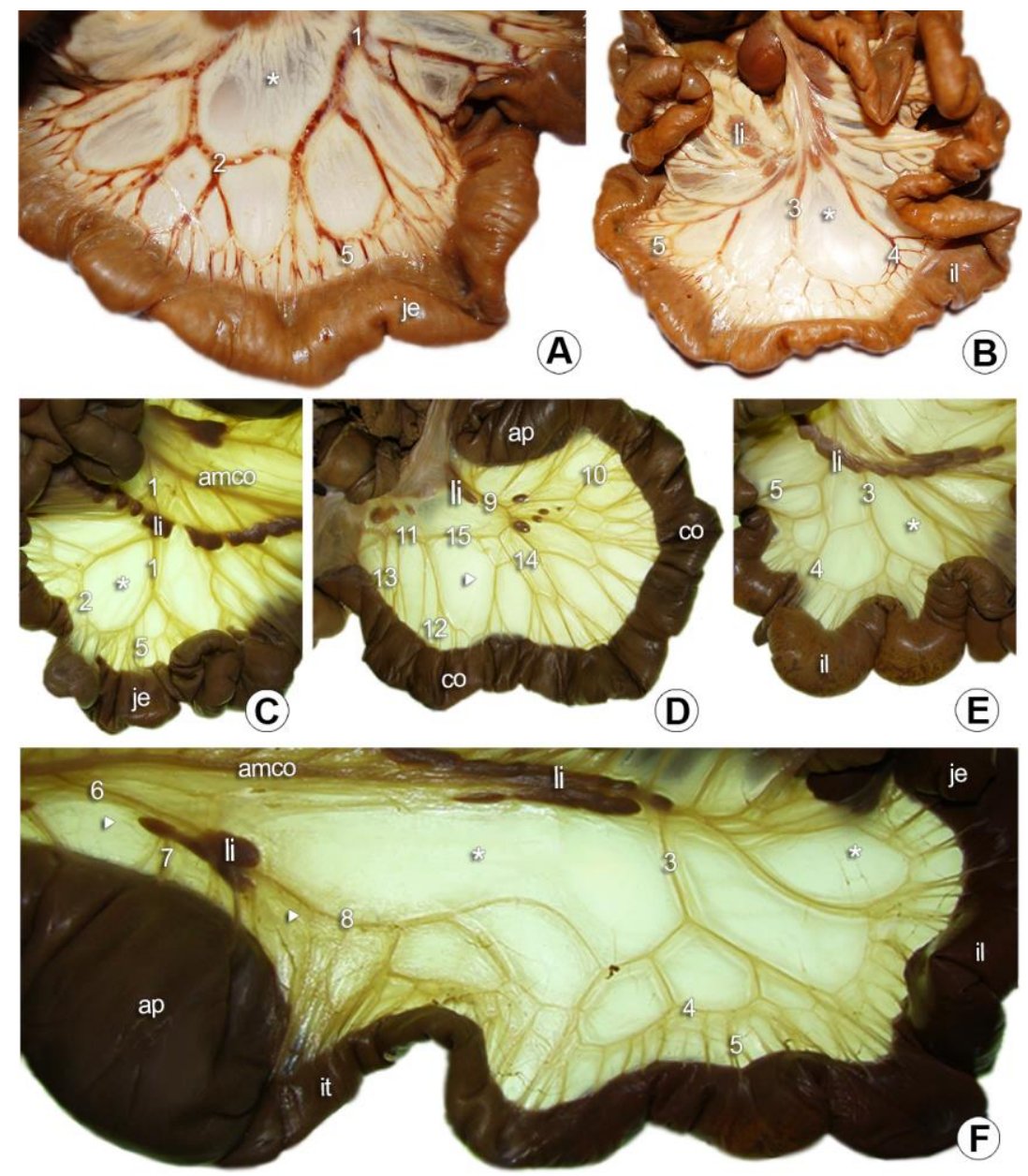

Figura 2: Imagens digitalizadas dos intestinos delgado e grosso de tatus: Euphractus sexcinctus (A e B) $e$ Dasypus novemcinctus (C, D, E e F), observa-se detalhes de vasos sanguíneos e dos linfonodos contidos no mesentério comum: primeiro, aspectos da morfologia externa intestinal, jejuno (je; A, C), íleo (il; B e E), íleo terminal (it; F), ampola cecal (ap; F), cólon (co; D); segundo, detalhes dos vasos e dos linfonodos mesentéricos e mesocólicos (A, B, C, D, E, F) a estes associados. Distribuição dos vasos intestinais (amco) e linfonodos mesentéricos, e os ramos colaterais primários, secundários terciários e arqueados das artérias jejunais (1), jejunal arqueada (2), ileal (3); ileal arqueada (4), ramo terminal justaintestinal (5), ileocólica (6), ramos justacecais (7), anastomose cecoileal (8). Vasos e linfonodos mesocólicos: ramo cólico da artéria cecocólica (9), ramo cólico arqueado (10), artéria retal (11), ramo arqueado da artéria retal (12), ramo terminal da artéria retal (13), ramo terminal da artéria cecocólica (14) e anastomose entre ramo da artéria cecocólica e a artéria retal (15). Detalhes do mesentério (*), mesocólon ( $\triangleleft)$ e dos linfonodos mesentéricos e mesocólicos (li).

Observou-se que da porção média da amco derivou-se um ramo dorsal: a artéria cecoileal (aci) que irrigou, à direita, o mesentério ileal e, à esquerda, o ceco e uma parte do íleo terminal (Fig. 3). Linfonodos mesocólicos estiveram relacionados com estes dois vasos (Fig.1A e 2D). O cólon caudal e o reto foram nutridos pela artéria retal (Fig. 1A e 2D); esta representou um ramo colateral de fino calibre, derivado diretamente da aorta abdominal, que recebeu contribuições da acc (ramo terminal da amco). Linfonodos cólicos estão relacionados com estas artérias. As variantes anatômicas dos vasos derivados da aorta abdominal destinados aos intestinos nessas espécies, a amco e a ar, foram representadas em dois modelos básicos de vascularização, cujos esquemas estão demonstrados na Fig. 3. 
Ao longo do seu trajeto (comprimento), a amco exibiu uma sequência de ramos colaterais primários retos, cuja frequência diminuiu do jejuno em relação ao íleo. Os ramos arqueados (secundários) tiveram topografias diferentes no jejuno e no íleo, sendo os arcos arteriais mais bem definidos no jejuno. Entre as espécies, a quantificação de ramos colaterais primários foi semelhante e dados quantitativos informam o tamanho dos segmentos dos intestinos nas espécies estudadas (Tab. 1).

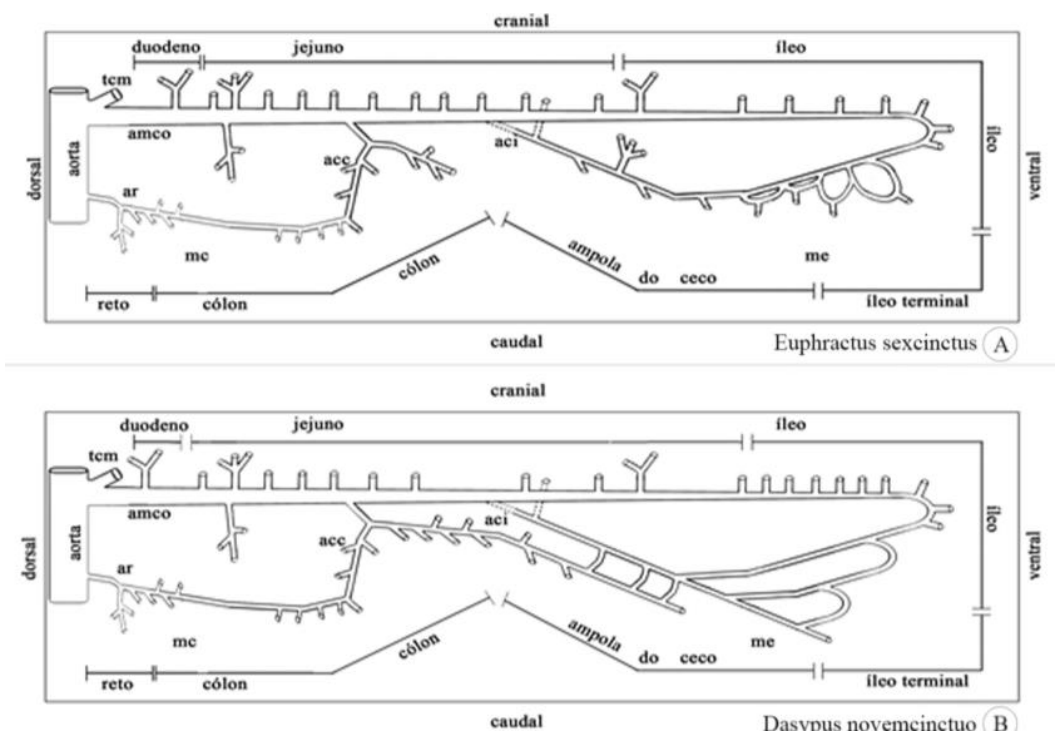

Figura 3. Representação esquemática do modelo de vascularização dos intestinos delgado e grosso de Xenarthras, Euphractus sexcinctus (A) e Dasypus novemcincus (B). Estão representados a aorta abdominal, o tronco celíaco mesentérico (tcm), a artéria mesentérica comum (amco) e a artéria retal (ar); os ramos colaterais primários destinados às diversas regiões dos intestinos delgado e grosso representados no esquema; os ramos caudodorsais da artéria cecocólica (acc) e sua anastomose com a artéria retal; os ramos caudoventrais da artéria cecoileal (aci) e sua anastomose com a porção ileal da amco; na zona de transição jejuno-ileal com a ampola do ceco, e na transição da anastomose da artéria cecocólica com a artéria cecoileal. Os termos dorsal, ventral, caudal e cranial indicam a localização espacial dos vasos em relação ao mesentério comum (me) e ao mesocólon (mc).

Tabela 1. Medidas, em centímetros, dos segmentos do intestino delgado, duodeno, jejuno e íleo, e do intestino grosso, ampola cecal e cólon, de duas espécies de tatus da biodiversidade brasileira (Euphractus sexcinctus e Dasypus novemcinctus), analisadas em função do número de animais, do sexo e da espécie

\begin{tabular}{|c|c|c|c|c|c|c|c|c|}
\hline \multirow{2}{*}{ Animal } & \multirow{2}{*}{ Sexo } & \multirow{2}{*}{ Espécie } & \multicolumn{4}{|c|}{$\begin{array}{c}\text { Intestino delgado } \\
(\mathrm{cm})\end{array}$} & \multicolumn{2}{|c|}{$\begin{array}{c}\text { Intestino grosso } \\
(\mathrm{cm})\end{array}$} \\
\hline & & & Duodeno & $\begin{array}{c}\text { Jejuno } \\
\text { e íleo }\end{array}$ & $\begin{array}{c}\text { Íleo } \\
\text { terminal }\end{array}$ & Total & $\begin{array}{c}\text { Ampola } \\
\text { cecal }\end{array}$ & Cólon \\
\hline 01 & $\mathrm{M}$ & E. sexcinctus & 27,0 & 389 & 12,0 & 428 & 14,0 & 58,0 \\
\hline 02 & $\mathrm{~F}$ & E. sexcinctus & 29,0 & 384 & 11,2 & 424,2 & 17,0 & 58,5 \\
\hline 03 & $\mathrm{~F}$ & E. sexcinctus & 27,1 & 410 & 14,3 & 451,4 & 15,2 & 62,8 \\
\hline 04 & M & E. sexcinctus & 27,2 & 436 & 12,0 & 475,2 & 12,0 & 64,6 \\
\hline Média & - & E. sexcinctus & 27,15 & 399,5 & 12 & 438,65 & 14,6 & 60,65 \\
\hline 05 & $\mathrm{~F}$ & D. novemcinctus & 31,0 & 476 & 12,0 & 519 & 11,0 & 51,0 \\
\hline 06 & $\mathrm{~F}$ & D. novemcinctus & 26,5 & 347 & 13,1 & 386,6 & 12,1 & 53,0 \\
\hline Média & - & D. novemcinctus & 28,75 & 411,5 & 12,55 & 452,8 & 11,55 & 52 \\
\hline Média Geral & - & - & 27,95 & 405,5 & 12,28 & 445.78 & 13,08 & 56,33 \\
\hline
\end{tabular}

Fonte: Dados de pesquisa do Laboratório de Macro e Mesoscopia, Faculdade de Medicina/UNB. Brasília 2012. 
Tabela 2. Comprimento da artéria mesentérica comum (amco) e quantificação de ramos arteriais colaterais primários dessa artéria destinados a segmentos dos intestinos delgado e grosso de duas espécies de tatus da biodiversidade brasileira (Euphractus sexcinctus e Dasypus novemcinctus), analisados em função do número de animais, do sexo e da espécie

\begin{tabular}{|c|c|c|c|c|c|c|c|c|}
\hline \multirow[b]{2}{*}{ Animal } & \multirow[b]{2}{*}{ Sexo } & \multirow[b]{2}{*}{ Espécie } & \multirow[b]{2}{*}{$\begin{array}{r}\text { amco } \\
(\mathrm{cm})\end{array}$} & \multicolumn{5}{|c|}{ Ramos colaterais primários } \\
\hline & & & & Duodeno & $\begin{array}{c}\text { Jejuno } \\
\text { e íleo }\end{array}$ & $\begin{array}{c}\text { Íleo } \\
\text { terminal }\end{array}$ & $\begin{array}{c}\text { Ampola } \\
\text { cecal }\end{array}$ & Total \\
\hline 01 & $\mathrm{M}$ & E. sexcinctus & 17,5 & 01 & 18 & 01 & 02 & 22 \\
\hline 02 & $\mathrm{~F}$ & E. sexcinctus & 19,4 & 01 & 20 & 01 & 01 & 23 \\
\hline 03 & $\mathrm{~F}$ & E. sexcinctus & 17,0 & 01 & 19 & 01 & 01 & 22 \\
\hline 04 & M & E. sexcinctus & 15,0 & 01 & 21 & 01 & 01 & 24 \\
\hline 05 & $\mathrm{~F}$ & D. novemcinctus & 16,5 & 01 & 22 & 01 & 01 & 25 \\
\hline 06 & $\mathrm{~F}$ & D. novemcinctus & 19,1 & 01 & 20 & 01 & 01 & 23 \\
\hline Média & - & - & 17,25 & 1 & 20 & 1 & 1 & 23 \\
\hline
\end{tabular}

Fonte: Dados de pesquisa do Laboratório de Macro e Mesoscopia, Faculdade de Medicina/UNB. Brasília 2012.

\section{DISCUSSÃO}

Interpretar os dados deste estudo considerando a localização dos Xenarthras na base filogenética dos mamíferos é indicativo da dificuldade de recuperação de trabalhos anatômicos da biodiversidade sul-americana que tem sido foco de poucas análises (Redford, 1985). Os autores menos contemporâneos inferem que, ao se estabelecerem comparações nas espécies estudadas, essas deveriam ser feitas com animais basais, visto que, nos mamíferos recentes, houve grandes aquisições evolutivas no que diz respeito à morfologia dos tubos digestórios (Llorca, 1952; Grassé, 1965; Noden e Lahunta, 1985). As alças intestinais na série animal, em geral, estão fixadas na parede dorsal por estruturas conjuntivas e mesoteliais; entre elas se destacam os ligamentos peritoneais, em várias topografias. Estas podem ser parcialmente peritonizadas ou retroperitoneais, o que foi consenso.

$\mathrm{Na}$ amostra pesquisada, o peritônio relacionado ao tubo digestório, ao fixar as vísceras abdominais, manteve-se pouco rotacionado, não coalescido, sem ligamentos densos direcionados à parede ventral abdominal, de forma diversa a outros mamíferos recentes descritos (Nickel et al., 1977; Moore e Persaud, 2008; Hyttel et al., 2010). Estudos destacaram que parte do intestino médio e terminal se apresentou fixada apenas na parede abdominal dorsal de Myrmecophagidae, havendo, neste caso, um mesentério conectado ao mesocólon (Souza et al., 2010; Ferreira et al., 2011), o que, de forma semelhante, confirmou-se nos Dasypodidae ora analisados. Desde a primeira alça intestinal, o duodeno, todas as outras estiveram conectadas por duplas membranas peritoneais cujo modelo de rotação, em relação ao peritônio parietal, exibiu um relativo grau de primitivismo (Grassé, 1955, 1965). Estudos em Bradypodidae reportaram-se a animais com alças duodenais peritonizadas, configurando-se um desenho basal de fixação na parede dorsal do corpo do animal (Rezende et al., 2011). Com relação ao intestino reto em Dasypodidae (Rezende e Ferreira, 2012), houve registro de relações peritoneais semelhantes às observadas nesta pesquisa.

A análise morfométrica de segmentos intestinais tem permitido o estabelecimento de comparação entre espécies estudadas. Entre estas, o Myrmecophaga tridactyla exibiu um intestino delgado sete vezes maior que o corpo, o Dasypus sabanicola 0,825 vez, e, na fêmea de Chaetophractus villosus, o valor de $0,910 \mathrm{vez}$ maior (Stevens e Hume, 1995; Diz et al., 2006). Este estudo analisou diversos setores do intestino, relacionando-os com a quantificação dos vasos por segmento intestinal. Interpretou-se que o jejuno foi mais vascularizado do que o íleo, o que pode ser indicativo de maior atividade metabólica. Esta suposição foi reforçada pela presença de vários linfonodos no trajeto dos vasos correspondentes às artérias jejunais.

Ao se interpretar a topografia dos intestinos delgado e grosso, notaram-se particularidades de sua fixação na cavidade visceral e na relação entre as vísceras. $\mathrm{O}$ mesentério suportou, na sua borda mesentérica, os segmentos conhecidos como jejuno, íleo, ampola cecal e cólon cranial, compartilhando estes a mesma lâmina serosa percorrida por vasos sanguíneos, linfáticos, cadeia de linfonodos e nervos, o mesentério comum. 
Essa topografia foi ao encontro do descrito em machos de tatus e tamanduás (Souza et al., 2010; Ferreira et al., 2011; Mortoza et al., 2013). Outros animais da família Myrmecophagidae tiveram seus mesentérios estudados, tendo o Tamandua tetradactyla e o Myrmecophaga tridactyla um mesentério comum medindo entre 20,42 e 36,4 centímetros de comprimento, respectivamente (Souza et al., 2010; Rezende et al., 2011), contra os 17,25 centímetros dos animais desta amostra. Comparando-se as diferenças nas proporções do mesentério, interpretou-se que os animais estudados, E. sexcinctus e D. novemcinctus, apresentaram um mesentério longo, semelhante ao registrado em Chaetophractus villosus (Diz et al., 2006), outra espécie da mesma família do continente sul-americano.

Como a história evolutiva não retroage, achou-se prudente não se estabelecerem comparações entre os Xenarthras com outros grupos de mamíferos. Entretanto, optou-se por destacar as diferenças existentes entre os modelos de rotação peritoneal apontados em estudos nas famílias Bradypodidae, Dasypodidae e Myrmecophagidae sobre aspectos de seus intestinos delgado e grosso. Comparados os resultados desta pesquisa aos de outros animais descritos, foi demonstrado que os Xenarthras têm intestinos mais simples no que diz respeito à estrutura morfológica de suas alças intestinais do ponto de vista macroscópico (Diz et al., 2006; Ferreira et al., 2011, 2013; Mortoza et al., 2013). Estudos de microanatomia, imagiologia e genética poderão elucidar muitas indagações sobre a morfofisiologia desses seres da natureza.

Há descrição de nove gêneros de tatus, divididos em quatro grupos de acordo com as suas especializações alimentares, sendo os Euphractus considerados carnívoro-onívoros ou generalistas (Redford, 1985). Os onívoros, em geral, exibem intestinos pós-pilóricos complexos (Grassé, 1955; Nickel, 1977). Nessa perspectiva, interpretou-se que tanto o intestino delgado quanto o intestino grosso tiveram "modelos de rotação e fixação basais", no que diz respeito às divisões por regiões intestinais, isto se interpretado relativamente aos mamíferos recentes. Houve uma diferença encontrada na fixação do intestino delgado, tendo sido esta a peritonização completa do duodeno e quase total do pâncreas nos $D$. novemcinctus.

Descrições de peritônios em vertebrados recentes (Llorca, 1952; Hyttel et al., 2010), confirmaram a complexidade da rotação peritoneal na região póspilórica na qual se acopla o duodeno e este, por sua vez, relaciona-se ao pâncreas e ambos, ao estômago; podendo estar o duodeno conectado indiretamente ao fígado e ao pâncreas pelos ductos excretores destas duas vísceras que desembocam na luz desta alça duodenal, o que, de forma semelhante, aconteceu neste estudo, embora o duodeno e grande parte do pâncreas não estivessem coalescidos à parede dorsal do corpo do animal.

O intestino delgado compartilhou a mesma artéria e o mesmo mesentério com grande parte do intestino grosso - o mesentério comum. A parte do peritônio que fixou o intestino delgado foi interpretada como mesentério, e a parte do peritônio que fixou os cólons foi interpretada como mesocólon, sendo as alças cólicas intraperitoneais, inclusive, a maior parte do intestino reto. A amco, portanto, destinou ramos colaterais ventrais e dorsais para os intestinos delgado e grosso, e, ao percorrer o espaço entre as lâminas peritoneais do mesentério comum, este vaso funcionalmente equivaleu a uma estrutura de reforço ligamentar, o que tem sido igualmente interpretado na maioria dos mamíferos.

O único reforço de fixação das alças intestinais na parede, além da raiz do mesentério, foi a contenção das alças intestinais pelo omento maior, que esteve fixado apenas na borda da grande curvatura do estômago, o que significou que há uma proteção apenas para alças de intestino delgado. Sendo esses animais fossórios, seus troncos são achatados dorsoventralmente, o que possibilita a localização das alças de intestino grosso nas regiões laterais de cada antímero corporal, em cujo espaço não é possível deslocamentos significativos. Quanto à morfologia externa do intestino grosso ao constatar-se na sua porção inicial uma dilatação reconhecida como ampola cecal no $D$. novemcinctus, esta esteve, na sua sequência, conectada a cólons lisos, enquanto no $E$. sexcinctus a porção inicial do intestino grosso, ao exibir uma alça pouco mais dilatada, não caracterizou muita diferenciação entre os intestinos delgado e grosso, sendo os cólons lisos ou retos. O intestino grosso, de uma maneira geral, ocupou posição espacial relativamente parecida com os intestinos de outros onívoros, embora sem fixações, coalescências e haustros, 
pela ausência de concentração de musculatura longitudinal ao longo do tubo intestinal.

A respeito do sistema arterial de mamíferos, tanto a literatura clássica como a recente vêm confirmando artérias mesentéricas derivadas diretamente da aorta (em roedores); em carnívoros, as artérias duodenais, jejunais e ileais totalmente intraperitoneais (Grassé, 1965; Machado et al., 2006; Culau et al., 2008; Lima et al., 2010, 2012), embora estudos em intestino delgado tenham apontado diferenças na origem da artéria mesentérica cranial, derivada da aorta como um ramo ventral independente. Esta artéria equivaleria à artéria mesentérica cranial dos Xenarthras ora descritos e equivalente à outra interpretação neste mesmo grupo animal (Mortoza et al., 2013).

Julgou-se poder concluir que os intestinos delgado e grosso do $D$. novemcinctus e do E.sexcinctus apresentaram diferenças de mamíferos recentes se aproximando da morfologia intestinal de animais basais. A topografia visceral confirmou um intestino póspilórico primitivo. Os intestinos delgado e grosso foram nutridos, em grande parte, por um ramo arterial compartilhado, a amco. Nesta série animal, até o momento, não foi relatada a presença de artérias mesentéricas cranial e caudal conforme reconhecidas em roedores e carnívoros, entre outros. Acredita-se que isto se deva a particularidades alimentares e evolutivas dos outros animais em relação aos Xenarthras.

Pode-se inferir que o aparecimento da artéria mesentérica caudal com independência da artéria mesentérica cranial, esta última como ramo ímpar e ventral da aorta abdominal, foi uma conquista dos vertebrados recentes. Foi possível concluir a existência de características específicas neste grupo estudado: duodeno e pâncreas intraperitoneais; ligamento duodenal caudal localizado na parede dorsal do antímero direito próximo ao útero (na fêmea) ou ao testículo (no macho); omento maior reduzido e fixado exclusivamente na grande curvatura do estômago; mesentério e mesocólon conectados no nível da ampola cecal; ausência de coalescência do peritônio à parede em todos os setores, inclusive no intestino reto; amco longa e derivada indiretamente da aorta abdominal através do tronco celíaco mesentérico; vasos intestinais abrigados no interior do mesentério e do mesocólon, envolvendo parte da ampola cecal, cólon cranial, flexuras cólicas e cólon reto, sendo os cólons lisos externamente.

O significado de o intestino grosso apresentar-se sem concentração de camadas musculares longitudinais externamente pode ser indicativo de uma musculatura intestinal com características funcionais menos sofisticadas fisiologicamente e de que o desenvolvimento de haustros e tênias bem definidas sejam conquistas dos vertebrados recentes. $\mathrm{O}$ estudo das características morfogenéticas dos animais basais encontrados na biodiversidade sul-americana poderia ser a chave para as respostas do surgimento de patologias estabelecidas nos intestinos dos animais recentes e objeto de pesquisas futuras.

\section{REFERÊNCIAS}

CULAU, P.O.V.; AZAMBUJA, R.C.; CAMPOS, $\mathrm{R}$. Ramos colaterais viscerais da artéria aorta abdominal em Myocastor coypus (nutria). Acta Sci. Vet., v.36, p.241-247, 2008.

DIZ, M.J.O.; QUSE, B.; GACHEN, G.G. Registro de medidas y pesos del tubo digestivo de un ejemplar de Chaetophractus villosus. Edentata, v.7, p.23-25, 2006.

FERREIRA, J.R.; REZENDE, L.C.; CARVALHO, P. et al. Modelo de suprimento sanguíneo do intestino delgado e grosso da preguiça de coleira (Bradypus torquatus). Ciênc. Rural, v.43, p.1114-1121, 2013.

FERREIRA, J.R.; SOUZA, A.L.R.; MORTOZA, A.R.; REZENDE, L.C. Vascularization of the small intestine in lesser anteaters, Tamandua tetradactyla (Xenarthra: Myrmecophagidae). Zoologia, v.28, p.488-494, 2011.

GRASSÉ, P.P. Ordre des Édentés. In: (Ed.). Traité de zoologie anatomie, systématique, biologie. Paris: Masson, 1955. p.1182-1246.

GRASSÉ, P.P. Traité de zoologie. Anatomie systématique, biologie vertébres: genéralites embriologie topographique, anatomie compare., Paris: Masson, 1965. Tome 12, 1129p.

HYTTEL, P.; SINOWATZ, F.; VEJLSTED, M.; BETTERIDGE, K. Development of the gastropulmonary system. In: SINOWATZ, F.; VEJLSTED, M. Essentials of domestic animal embryology. Edinburg: Saunders Elsevier, 2010. p.216-248. 
LIMA, E.M.M.; CARNEIRO E SILVA, F.O.; SEVERINO R.S. et al. Origem e ramificação da artéria mesentérica cranial em fetos de cães (canis familiaris) da raça american pit bull terrier. Biosci. J., v.28, p.265-269, 2012.

LIMA, V.M.; REZENDE, A.L.S.; FERREIRA, J.R.; PEREIRA, K.F. Distribuition of mesenteric cranial artery in the small intestine of Procyon carnivorus (Cuvier, 1798) (Mammalian, Procionídea). Acta Sci. Biol. Sci., v.32, p.175-179, 2010.

LLORCA, F.O. Intestino médio. In: Anatomia humana. Barcelona: Editorial Científico Médica, 1952. Tomo 3, cap.10, p.459528.

MACHADO, G.V.; GONÇALVES, P.R.; PARIZZI, A.; SOUZA, J.R. Padrão de distribuição das artérias mesentéricas no ratão-dobanhado (Mycocastor coypus - Rodentia: Mammalia). Biotemas, v.19, p.59-63, 2006.

MOORE, K.L.; PERSAUD, T.V.N. Embriologia clínica. 3.ed. Rio de Janeiro: Elsevier, 2008. 536p.

MORTOZA, A.R.; REZENDE, L.C.; OLIVEIRA, C.C.; FERREIRA, J.R. Distribution of arterial supply to the large intestine in the anteater (Tamandua tetradactyla). Zool. Sci., v.30, p.670-674, 2013.

NICKEL, R.; SCHUMMER, A.; SACK, W.O.; SEIFERLE, E. The alimentary canal, general and comparative. In: Anatomy of the domestic mammals. 2.ed. Hamburg: Verlog Paul Parey, 1977. p.99-203.
NODEN, D.M.; LAHUNTA, A. The embryology of domestic animals. Developmental mechanisms and malformation. Baltimore: Williams e Wilkins, 1985. 367p.

REDFORD, K.H. Ecology of living armadillos. In: MONTGOMERY, G.G. (Ed.). The evolution and ecology of armadillos, sloths, and vermilinguas. Washington / London: Smithsonian Institution Press, 1985. p.429-437.

REZENDE, L.C.; FERREIRA, J.R. Pelvic peritoneum in pale armadillo and anteater (Xenarthra, Mammalia): a comparative survey. Zool. Sci., v.30, p.60-64, 2012.

REZENDE, L.C.; MONTEIRO, J.M.; FERREIRA, J.R. et al. Morphology and vascularization of the gastric compartments in Three-Toed Sloth (Bradypus torquatus Illiger, 1811), Int. J. Morphol., v.29, p.1282-1290, 2011.

SOUZA, A.L.R.; REZENDE, L.C.; MORTOZA A.R.; FERREIRA, J.R. Modelo de suprimento sanguíneo do intestino grosso do tamanduá bandeira (Mymercophaga tridactyla). Ciênc. Rural, v.40, p.541-547, 2010.

STEVENS, C.E.; HUME, I.E. Comparative physiology of the vertebrate digestive system. Cambrigde: Cambrigde University Press, 1995. 400p. 